\title{
Avaliação do Ciclo de Vida de sistemas de tratamento de efluentes urbanos utilizando Microalgas e Wetlands Construídos
}

\author{
Life Cycle assessment of urban effluent treatment systems \\ using Microalgae and Constructed Wetlands
}

Naira Dell'Osbel', Ênio Leandro Machado"

\section{Resumo}

Desenvolver o saneamento de águas residuárias de forma descentralizada significa pesquisar a carência de quase $50 \%$ dos municípios brasileiros. Neste sentido a principal finalidade deste estudo foi o uso da Avaliação do Ciclo de Vida para aplicação dos sistemas integrados de reator anaeróbio, Wetlands Construídos (WCs) de fluxo vertical/ horizontal e Microalgas (MA). A unidade funcional foi definida como $1.200 \mathrm{~m} 3$ de efluente tratado durante 20 anos e a fronteira do sistema foi delimitada pela entrada do esgoto bruto no reator UASB até a partida do efluente final tratado para o corpo receptor. O estudo de ACV utilizou o programa SimaPro ${ }^{\circledR} 8.04$ e o método Impact 2002+. Para as categorias de impacto nas etapas de construção e operação foram aplicados a Normalização, Caracterização, Ponderação e Inventário de Rede dos dados obtidos. Desta forma foi possível a identificação dos principais itens para o desenvolvimento ambiental sustentável destes sistemas, sendo que foram identificados os maiores impactos na fase de construção (92,3\%) relacionados a utilização de polietileno de alta densidade (32,8\%), areia (27,2\%) e policloreto de vinila (18,8\%). Já na fase de operação o maior impacto foi a utilização de energia elétrica no sistema Microalgas PréWetlands devido a dependência de recursos não renováveis.

Palavras-chave: Avaliação do ciclo de vida; Efluente doméstico; Wetlands construídos; Microalgas

\section{Abstract}

Developing wastewater sanitation in a decentralized way makes it possible to study the shortage of almost $50 \%$ of Brazilian municipalities. Thus, the main purpose of this study was the use of the Life Cycle Assessment for the application of the integrated systems of anaerobic reactor, Wetlands Constructed (WCs) of vertical/horizontal flow and Microalgas (MA). The functional unit was defined as 1,200 m3 of effluent treated for 20 years, and the boundary of the system was delimited by the entry of the raw sewage into the UASB reactor until the departure of the final effluent treated to the receiving body. The ACV study used the SimaPro ${ }^{\circledR} 8.04$ program and the Impact 2002+ method. For the categories of impact in the construction and operation stages were applied the Normalization, Characterization, Weighting and Network Inventory of the obtained data. Through it was possible to identify the main items for the sustainable environmental development of these systems, with the highest impacts in the construction phase (92.3\%) related to the use of high density polyethylene (32.8\%), sand $(27.2 \%)$ and polyvinyl chloride (18.8\%). Already in the operation phase the greatest impact was the use of electricity in the Microalgas Pre-Wetlands system due to the dependence of non-renewable resources.

Keywords: Life cycle assessment; Domestic effluent; Contructed wetlands; Microalgae 


\section{Introdução}

No Brasil ainda existem locais de extrema pobreza e desigualdade onde se evidenciam a falta de acesso sustentável a água potável, assim como carência de infraestrutura de saneamento, principalmente em áreas rurais e urbanas carentes. Isso coloca a população local em situação de risco a saúde individual e coletiva, aumentando a incidência de doenças infecciosas agudas e a prevalência de doenças crônicas, que atingem principalmente pessoas mais vulneráveis (GEORGIN et. al., 2014).

Fatores como a escassez de sistemas de tratamento de efluente doméstico em pequenos municípios e na zona rural, bem como a expansão atual de condomínios residenciais, aumentam a necessidade de sistemas de tratamento de efluentes domésticos compactos e simplificados no Brasil (GUTIERREZ, 2014).

Uma das alternativas sustentáveis para o gerenciamento integrado de recursos hídricos e que vem despertando interesse no mundo inteiro é o uso de vegetação para remediação de águas servidas, sendo uma possibilidade de manutenção da qualidade dos mesmos (COSTA, 2004).

A utilização de wetlands construídos com macrófitas aquáticas é uma alternativa para a falta de tratamento das águas residuais, que afeta principalmente as zonas rurais do Brasil, sendo que essas áreas não apresentam problemas em relação à falta de espaço, mas sim a necessidade de tecnologias simples, econômicas e que exigem pouca energia, desta forma pode-se dizer que a utilização desses sistemas é uma alternativa viável, natural, sustentável e eficaz (PHILIPPI \& SEZERINO, 2004).

Os princípios básicos de funcionamento do tratamento nos filtros plantados são a filtração e a formação de biofilme aderido a um meio suporte e as raízes das plantas, onde comunidades de microrganismos aeróbios e anaeróbios depuram a matéria orgânica e promovem a nitrificação e desnitrificação. O oxigênio requerido é suprido pelas macrófitas e pela convecção e difusão atmosférica (PHILIPPI \& SEZERINO, 2007).

Outra alternativa que tem se mostrado muito promissora e sustentável é a utilização de microalgas para tratamento de águas servidas, pois através do desenvolvimento destes sistemas é possível a fixação do dióxido de carbono proveniente dos gases de combustão e a remoção dos nutrientes das águas residuais, podendo ser utilizada inclusive para a fixação do $\mathrm{CO}_{2}$ produzido por complexos industriais (SOUSA, 2014).

As microalgas fazem parte da comunidade biótica que se desenvolve nos sistemas de tratamento em lagoas, sendo que o funcionamento destes sistemas se baseia na combinação de processos metabólicos entre as populações bacterianas, que mineralizam a matéria orgânica, e as microalgas, que utilizam como nutrientes os produtos dessa degradação (SOARES, 2000).

A Avaliação do Ciclo de Vida contribui como uma ferramenta complementar em momentos de tomada de decisão entre sistemas de tratamento de efluentes domésticos, sendo que ela é capaz de avaliar o desempenho ambiental da função exercida por um processo ao longo de seu ciclo de vida, no entanto, é preciso estar ciente de que o sucesso no uso da ACV é diretamente dependente do uso de inventários de ciclo de vida (ICV) regionalizados. Há uma grande variedade de iniciativas ao redor do mundo com o objetivo de padronizar os estudos e construir um banco de dados específico (GUTIERREZ, 2014).

Em áreas rurais os sistemas integrados de processos anaeróbios e wetlands construídos são uma nova tendência de desenvolvimento sustentável, que possibilita a recuperação de materiais, energia e nutrientes, sendo essencial para tecnologias de saneamento que combinam baixos custos, alta eficiência e menor pressão ambiental (LUTTERBECK et. al., 2017).

Visto as necessidades de sustentabilidade em longo prazo, os objetivos dos sistemas de tratamento precisam ir além da proteção da saúde humana e das águas superficiais, minimizando também a perda de recursos, redução do uso de energia e água, reduzindo a geração de resíduos e permitindo a reciclagem de nutrientes (COROMINAS, 2013).

Buscando identificar os impactos relacionados com a biorremediação por sistemas de Microalgas e Wetlands Construídos, foi aplicada uma Avaliação do Ciclo de Vida, estabelecendo comparativo com mesma unidade funcional e fluxo de referência para o tratamento em diferentes configurações. Utilizou-se o programa SimaPro ${ }^{\circledR}$ para calcular impactos associados ao processo, verificando possibilidades de prognósticos ambientais.

\section{Metodologia}

$\mathrm{Na}$ fase de construção foram inventariados todos os materiais utilizados, bem como os necessários para troca do leito a cada 5 anos de trabalho, totalizando uma vida útil total de 20 anos. Na fase de operação foram quantificadas as emissões para a água através de análises do efluente líquido realizadas em laboratório determinando os parâmetros de $\mathrm{DBO}_{5}$, DQO, Nitrogênio Amoniacal, Nitrato, Nitrito, Nitrogênio Total Kjeldahl e Fósforo Total (Standard Methods for the Examination of Water and Wastewater, 2012). Para as emissões atmosféricas foi utilizado o modelo matemático fornecido pelo relatório do Intergovernmental Painel Climate Change - IPCC (2013) sobre sistemas de wetlands. A unidade funcional foi definida em $1.200 \mathrm{~m}^{3}$ de efluente final tratado durante 20 anos, sendo que a fronteira do sistema foi delimitada pela entrada do esgoto bruto no reator anaeróbio até a partida do efluente final tratado para o corpo receptor.

O estudo de ACV baseou-se nas normas da NBR ISO 14040 e 14044 , utilizando o programa SimaPro ${ }^{\circledR} 8.04$ e o método do Impact 2002+ para as categorias de impacto nas etapas de construção e operação: Carcinogênicos, Não Carcinogênicos, Inorgânicos Inaláveis, Radiação Ionizante, Depleção da Camada de Ozônio, Orgânicos Inaláveis, Ecotoxicidade Aquática, Ecotoxicidade Terrestre, Acidificação Terrestre, Ocupação do Solo, Acidificação Aquática, Eutrofização Aquática, Aquecimento Global, Energia Não Renovável e Extração Mineral. 
Foram considerados 2 Cenários diferentes de avaliação, sendo que ambos são precedidos por sistema de gradeamento, desarenação e equalização. O Cenário I é o sistema em escala de bancada e é constituído por Reatores Anaeróbios + Microalgas + WC de Fluxo Vertical, já o Cenário II é o sistema em escala piloto e é constituído por 2 configurações distintas, uma com Reatores Anaeróbios+WC Fluxo Vertical e a outra com Reator Anaeróbio+WC Fluxo Horizontal conforme Figura 1.

O Cenário I é constituído por uma caixa em PEAD de 200 litros com cone em acrílico para fixação das microalgas e bomba de recirculação de $110 \mathrm{~W}$ com potência de deslocamento de $1,5 \mathrm{~m} \mathrm{~h}^{-1}$ de coluna d'água, a qual funcionou 24 horas por dia (Figura $2 b$ ). A segunda caixa constitui o Wetland Construído, tendo a mesma capacidade da caixa das microalgas, porém a mesma é preenchida com camadas de brita ${ }^{\circ} 4$, brita $n^{\circ} 1$, areia e plantada com a espécie Hymenachne Grumosa (Figura 2c). Ainda como tratamento primário é utilizado sistema de reatores anaeróbios constituídos por 3 bombonas, em polietileno, com capacidade de 90 litros cada (Figura 2a).

O Cenário II é constituído por caixas d'água de 1.000 litros em fibra de vidro, brita $\mathrm{n}^{\circ} 1$, brita $\mathrm{n}^{\circ} 2$, registros, tubulações e conexões, sendo que nas caixas foram plantados indivíduos da espécie Hymenachne grumosa, mais conhecida como Carnivão. A escolha da espécie se deve ao fato de ser uma planta nativa da região e bem adaptada às condições encontradas em sistemas alagados. Foram

Figura 1 - Delimitação dos sistemas de tratamento analisados

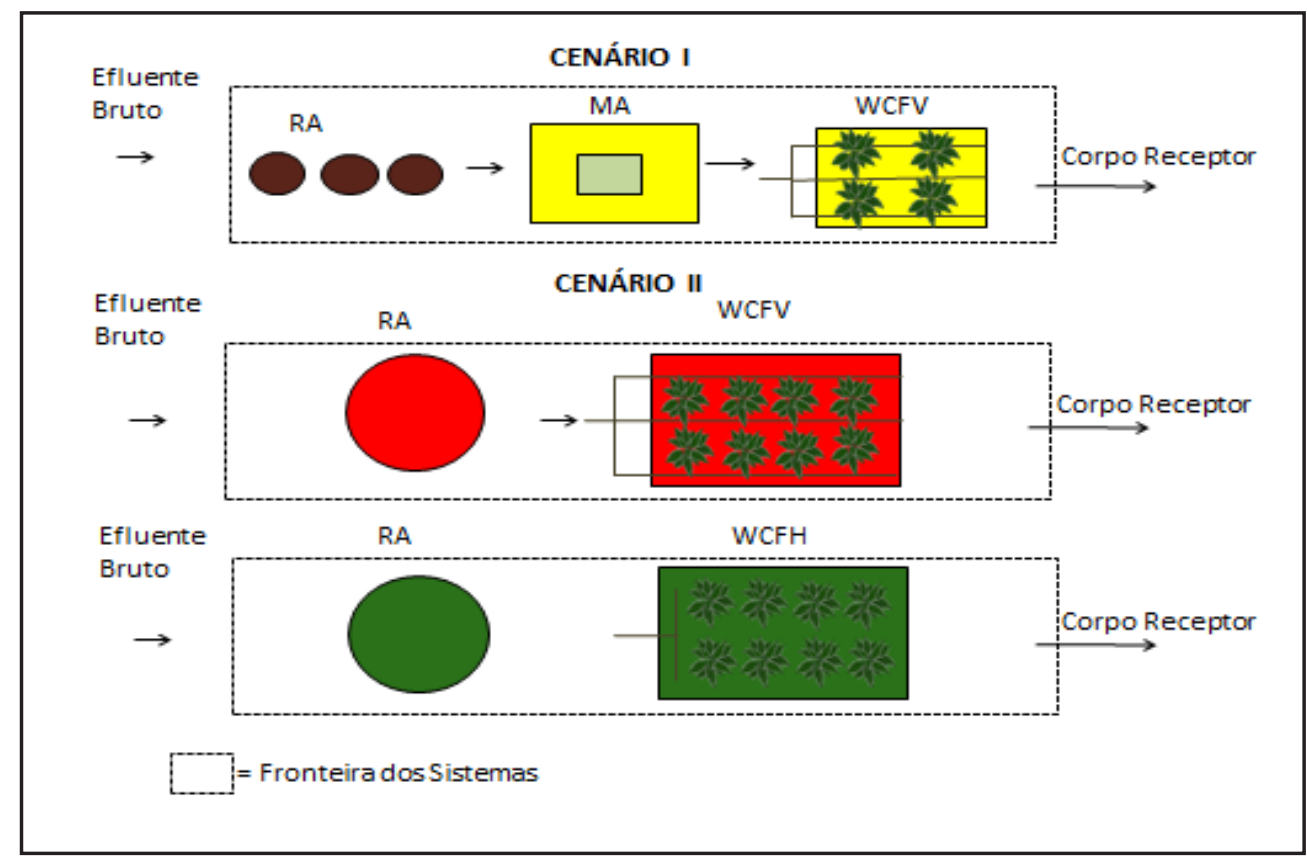

Fonte: Autores

Figura 2-Cenário I: (a) Reator Anaeróbio + (b) Unidade Fixadora de Microalgas com Cone Invertido +(c) Wetland Construído de Fluxo Vertical em regime de batelada

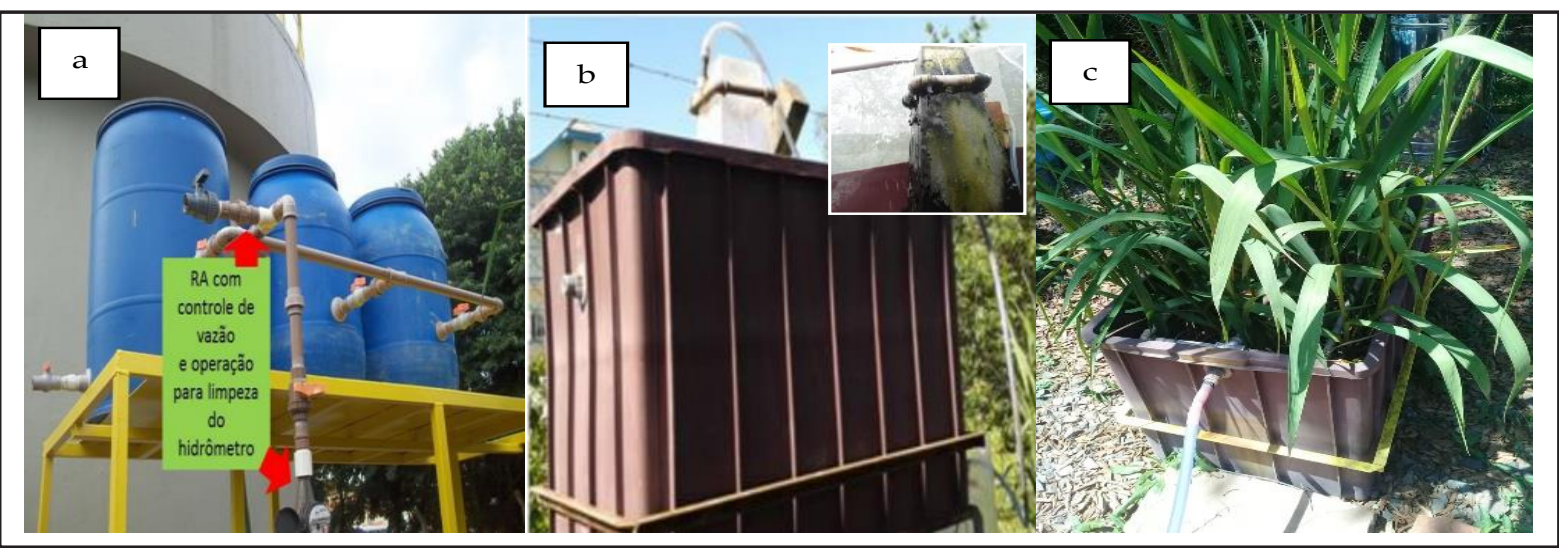

Fonte: Autores 
Figura 3 - Cenário II - Reator Anaeróbio (a) Wetland Construído de Fluxo Vertical (b) e Wetland Construído de Fluxo Horizontal (c)

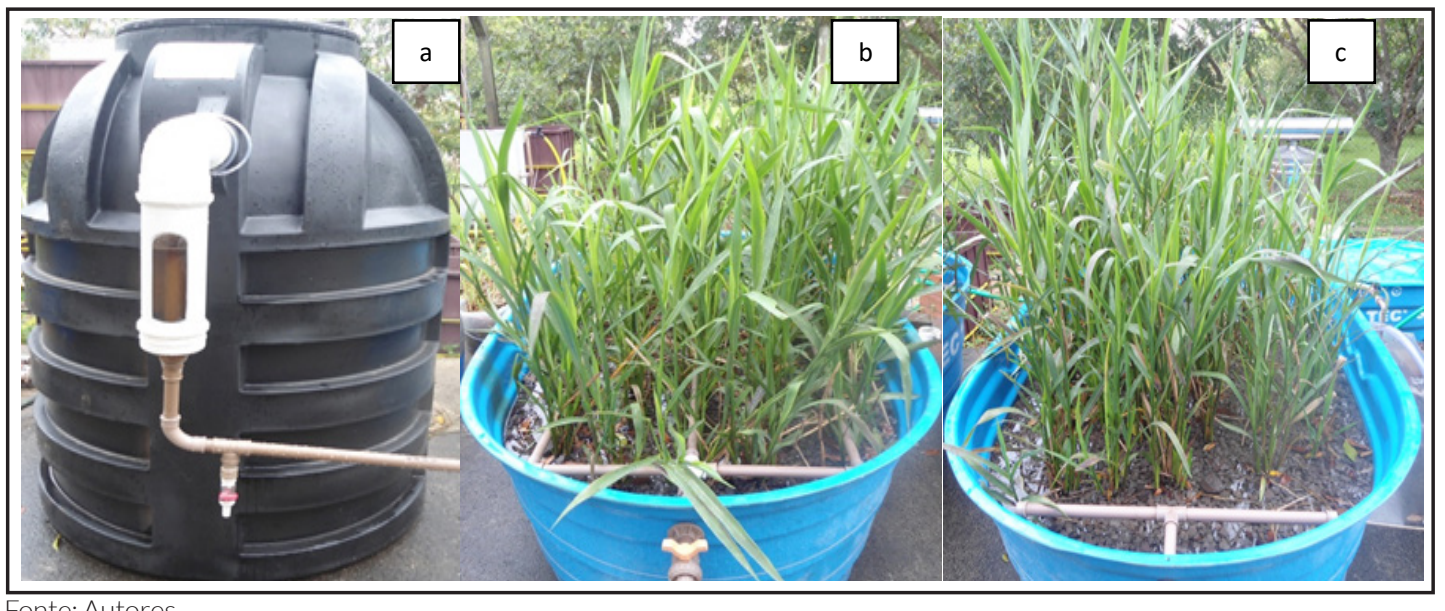

utilizados dois diferentes tipos de fluxos conforme Figuras 3 (b) na qual está demonstrado o WC de Fluxo Vertical e 3 (c) na qual pode-se observar o sistema de WC de Fluxo Horizontal, sendo que os sistemas recebem tratamento primário no Reator Anaeróbio apresentado na Figura 3 (a).
Foi feita extrapolação proporcional dos materiais para igualar os sistemas e de modo que se considere para ambos a capacidade de tratar $1.200 \mathrm{~m}^{3}$ de efluente em 20 anos. Na Tabela 1 e 2 estão apresentados os dados inventariados para o presente estudo.

Tabela 1 - Inventário do Cenário I

\section{CENÁRIO I}

Etapa: construção

\section{Tonéis RA (PEAD)}

Tubulações (PVC)

Brita

Areia

Caixas (PEAD)

Cone (acrílico) para fix. das Microalgas

Areia e Brita para troca dos leitos

Bomba Recirculação Microalgas

\section{Massa total do sistema $(\mathrm{kg})$}

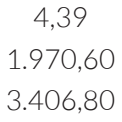

25,05

\begin{tabular}{|c|c|c|c|c|}
\hline Emissões para a água (kg em 20 anos) & DQO & $\mathrm{DBO}_{5,20}$ & $\mathrm{~N}-\mathrm{NH}_{4}$ & Fósforo Total \\
\hline RA & 408,24 & 418,2 & 104,5 & 7,8 \\
\hline MA & 497,8 & 636 & 0 & 5,58 \\
\hline WCFV & 596,4 & 472,8 & 0 & 6,24 \\
\hline Emissões para o ar (kg em 20 anos) & $\mathrm{CH}_{4}$ & $\mathrm{~N}_{2} \mathrm{O}$ & & \\
\hline RA & 109,92 & 0,36 & & \\
\hline MA & 131,3 & 1,32 & & \\
\hline WCFV & 33,07 & 1,3 & & \\
\hline
\end{tabular}


Tabela 2 - Inventário do Cenário II

CENÁRIO II

\begin{tabular}{|c|c|c|c|c|c|c|}
\hline Etapa: construção & Massa total do sistema (kg) & & & & & \\
\hline Brita 1 e 2 & 7772 & & & & & \\
\hline Reator UASB (polietileno) & 110 & & & & & \\
\hline Registro de gaveta (liga de cobre) & 2,28 & & & & & \\
\hline Tubos e conecções (PVC) & 13 & & & & & \\
\hline Caixa d'água (fibra de vidro) 1000 I & 52,5 & & & & & \\
\hline \multicolumn{7}{|l|}{ Etapa: operação } \\
\hline Emissões para a água (kg em 20 anos) & $\mathrm{DBO}_{5}$ & DQO & $\begin{array}{c}\text { Fósforo } \\
\text { Total }\end{array}$ & Nitrato & Nitrito & NTK \\
\hline RA & 100,32 & 256,77 & 28,08 & 0,48 & 0,12 & 106,8 \\
\hline WCFV & 61,68 & 139,5 & 10,8 & 0,12 & $<0,0000001$ & 15,12 \\
\hline WCFH & 84,12 & 186 & 10,1 & 0,12 & $<0,0000001$ & 13,7 \\
\hline Emissões para o ar (kg em 20 anos) & $\mathrm{CH}_{4}$ & $\mathrm{~N}_{2} \mathrm{O}$ & & & & \\
\hline RA & 38,9 & 0,24 & & & & \\
\hline WCFV & 11,16 & 0,83 & & & & \\
\hline WCFH & 2,3 & 0,85 & & & & \\
\hline
\end{tabular}

\section{Resultados e Discussões}

\subsection{Inventário de Rede dos Sistemas}

A partir dos dados levantados e analisados pode-se concluir que a operação destes tipos de sistemas é minimamente impactante, se levarmos em conta que foi estimado um período de operação razoável. Através do Inventário de Rede pode-se observar que a etapa de construção contribui com $92,3 \%$ e, a operação, durante os 20 anos, contribui com apenas $7,7 \%$ do total de impactos relacionados aos sistemas (Figura 4).

Observou-se que os materiais com maiores contribuições para fins de impactos ambientais foram o PEAD, PVC e a areia, que somados representam mais de $78 \%$ dos impactos relacionados a etapa de construção, conforme apresentado na Figura 5.

O principal impacto negativo do wetland construído aqui estudado foi causado pela fase de construção e uso de agregado de argila expandida para construir o sistema, isso ocorre porque grande quantidade de energia é usada
Figura 5 - Contribuição de cada material na etapa de construção

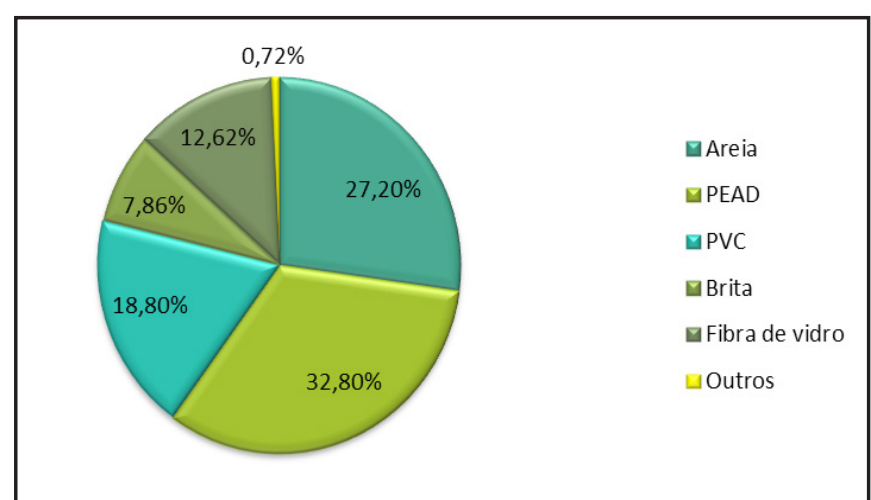

Fonte: Autores

para produzir esse material. Foi testado como alternativa o uso de um filtro de areia e cascalho e de acordo com os resultados, um filtro de areia e cascalho diminuiria o impacto médio do WC em 22,91\% (LOSPISIK et. al. 2013).

Figura 4 - Inventário de Rede obtido no Software SimaPro® 8.04

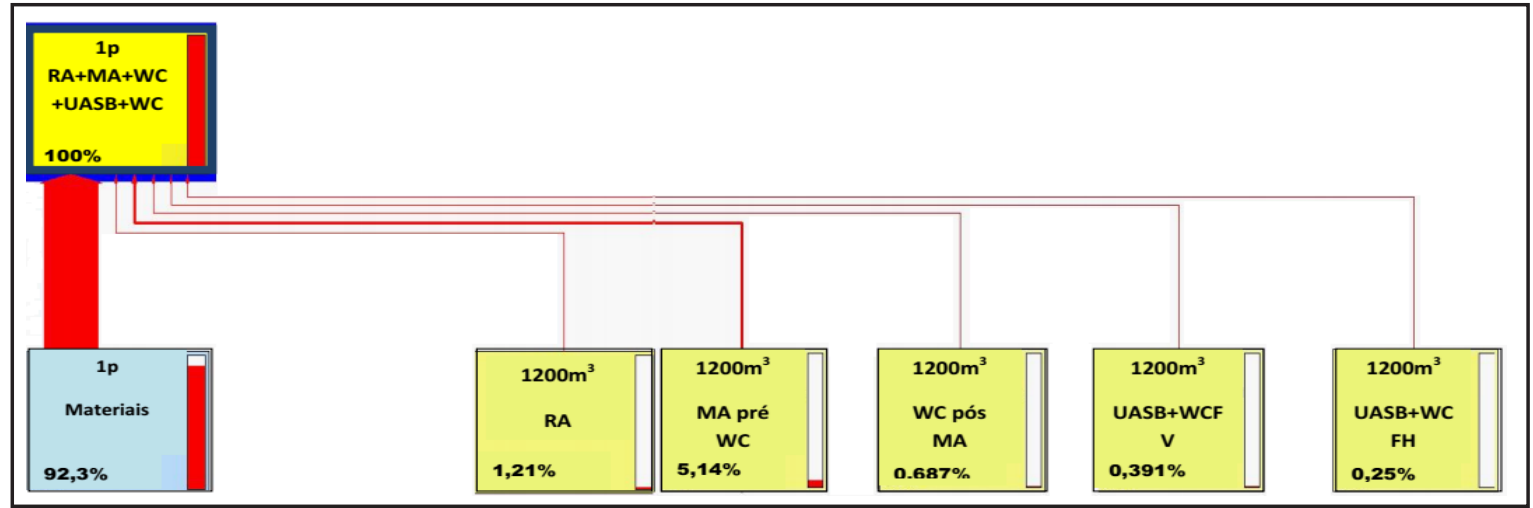

Fonte: Autores 
Conforme Fuchs et.al. (2017) os impactos da construção podem ser significativamente reduzidos usando materiais locais para evitar o transporte. No presente trabalho esse é um item que pode gerar incertezas, pois foi utilizado um banco de dados não regionalizado, porém os resultados poderiam ter sido bem mais favoráveis eliminando-se os custos econômicos e ambientais do transporte dos materiais, visto que a brita utilizada nos sistemas é oriunda de mina de extração localizada próxima a área de concretização do presente estudo.

\subsection{Análise da Etapa de Construção}

Com relação aos impactos associados aos inventários da Figura 4, podem ser observadas a Caracterização e Normalização nas Figuras 6 e 7.
Em avaliação de ciclo de vida de sistema de tratamento de efluentes com processo anaeróbio+ wetlands construídos+fotorreatores para áreas rurais realizado por Lutterbeck et. al. (2017) constatou-se que 67,3\% dos impactos ambientais estavam relacionados à construção e apenas $32,7 \%$ à operação do sistema.

Através da técnica de normalização é possível visualizar que os maiores impactos estão relacionados aos carcinogênicos, não carcinogênicos, inorgânicos inaláveis, ecotoxicidade terrestre, aquecimento global e recursos não renováveis.

Na etapa de construção o sistema de Microalgas aparece em destaque, sendo que se atribui a esse fato a maior utilização de materiais plásticos, devido a utilização no Cenário I (RA+MA+WCFV) das caixas em polietileno e areia, materiais que não foram utilizados no Cenário 2.

Figura 6 - Caracterização utilizando o método Impact 2002+ da etapa de Construção

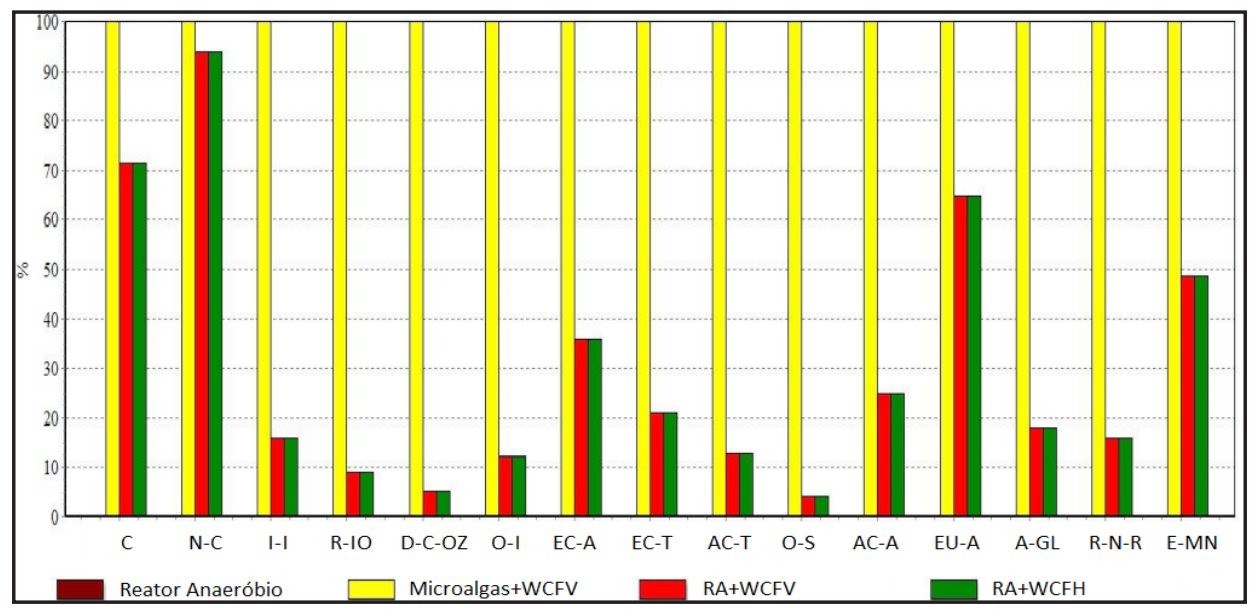

C: Carcinogênicos; N-C: Não Carcinogênicos; I-I: Inorgânicos Inaláveis; R-IO: Radiação lonizante; D-C-OZ: Depleção da Camada de Ozônio; O-I: Orgânicos Inaláveis; EC-A: Ecotoxicidade Aquática; EC-T: Ecotoxicidade Terrestre; AC-T: Acidificação Terrestre; O-S: Ocupação do Solo; AC-A: Acidificação Aquática; EU-A: Eutrofização Aquática; A-GL: Aquecimento Global; R-N-R: Recursos Não Renováveis; E-MN: Extração Mineral. Fonte: Autores

Figura 7 - Normalização utilizando o método Impact 2002+ da etapa de Construção

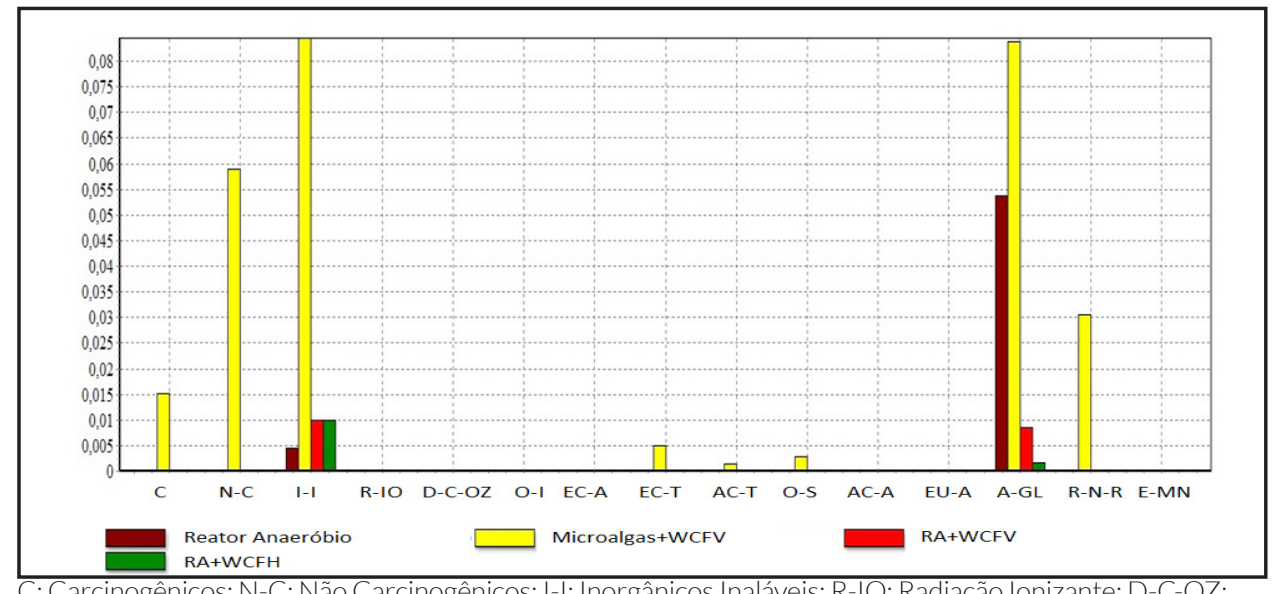

C: Carcinogênicos; N-C: Não Carcinogênicos; I-I: Inorgânicos Inaláveis; R-IO: Radiação lonizante; D-C-OZ: Depleção da Camada de Ozônio; O-I: Orgânicos Inaláveis; EC-A: Ecotoxicidade Aquática; EC-T: Ecotoxicidade Terrestre; AC-T: Acidificação Terrestre; O-S: Ocupação do Solo; AC-A: Acidificação Aquática; EU-A: Eutrofização Aquática; A-GL: Aquecimento Global; R-N-R: Recursos Não Renováveis; E-MN: Extração Mineral Fonte: Autores 
Figura 8 - Ponderação utilizando o método Impact 2002+ para a etapa de Construção

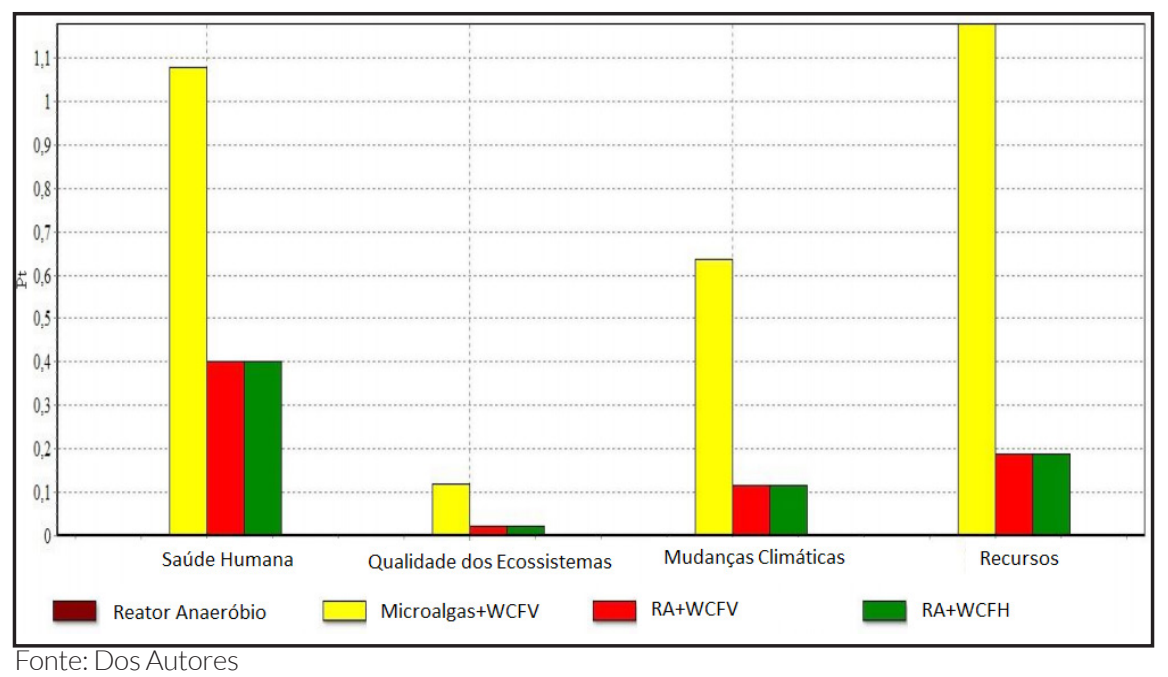

Conforme Silva (2015) o processo produtivo na indústria de transformação do plástico necessita de muita energia elétrica, o contribuindo para as categorias de impacto, seguido pelo processo de transporte de matérias-primas e do produto final por conta da utilização do diesel, o que pode ser melhorado com a implantação da eficiência energética na própria indústria.

Já na Figura 8 estão apresentados os impactos em longo prazo gerados através da ponderação, destacando-se novamente o sistema de Microalgas.

\subsection{Análise da Etapa de Operação}

Foi utilizada a mesma metodologia na análise da operação dos sistemas, na Figura 9 que representa a Caracterização já podemos visualizar os sistemas com os maiores impactos.

Conforme Fuchs et. al. (2011) os estudos de ACV mostram que os WC têm menos impacto ambiental, em termos de consumo de recursos e emissões de gases de efeito estufa, concluindo também que os WC tanto de fluxo horizontal como vertical têm impactos insignificantes em orgânicos respiratórios, radiação e ozônio. Também constatou que $\mathrm{N}_{2} \mathrm{O}, \mathrm{CO}_{2}$ e $\mathrm{CH}_{4}$ influenciam em inorgânicos inaláveis, mudanças climáticas, acidificação e eutrofização, categorias com maior influência em Alterações Climáticas.

Temos o sistema de microalgas pontuando de forma significativa em 8 tipos de impactos diferentes e aparece de forma significativa o reator anaeróbio contribuindo para os inorgânicos inaláveis e aquecimento global conforme Figura 10.

Na ponderação (Figura 11) pode-se observar que na etapa de operação o sistema de tratamento com Microalgas tem um impacto maior em todas as categorias analisadas, atribui-se a isso a utilização de energia elétrica para a bomba que mantém o efluente em recirculação de forma contínua para que as microalgas não morram.

Figura 9 - Caracterização utilizando o método Impact 2002+ da etapa de Operação

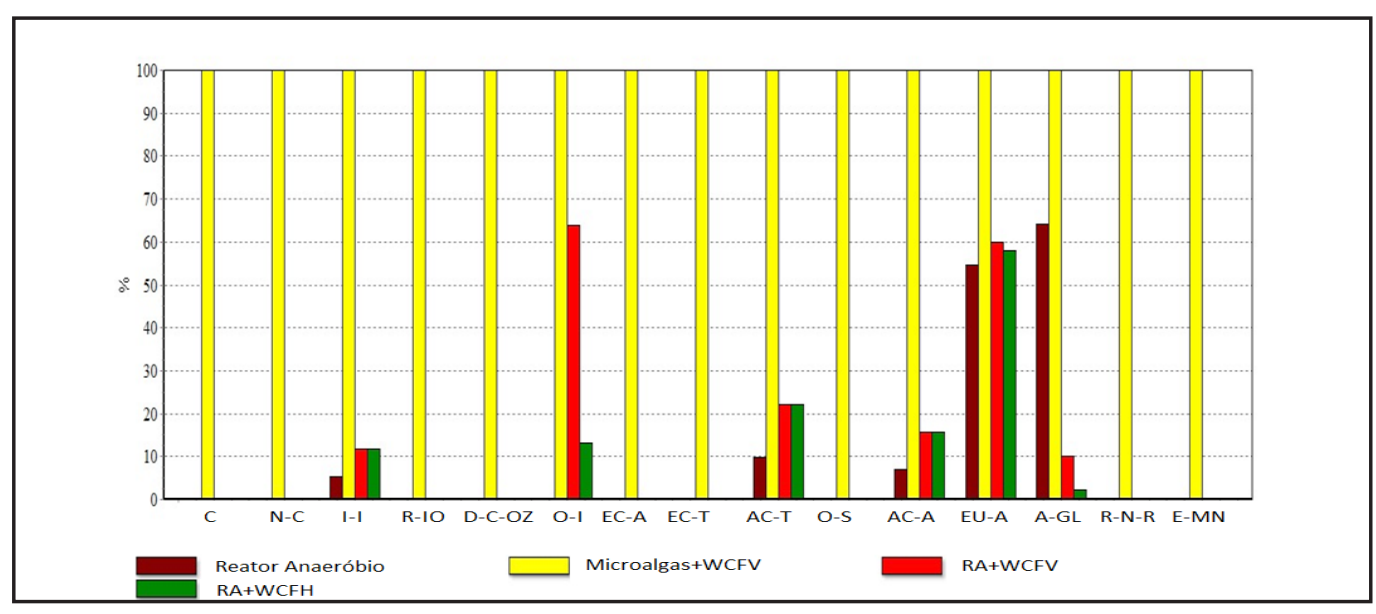

C: Carcinogênicos; N-C: Não Carcinogênicos; I-I: Inorgânicos Inaláveis; R-IO: Radiação Ionizante; D-C-OZ: Depleção da Camada de Ozônio; O-I: Orgânicos Inaláveis; EC-A: Ecotoxicidade Aquática; EC-T: Ecotoxicidade Terrestre; AC-T: Acidificação Terrestre; O-S: Ocupação do Solo; AC-A: Acidificação Aquática; EU-A: Eutrofização Aquática; A-GL: Aquecimento Global; R-N-R: Recursos Não Renováveis; E-MN: Extração Mineral Fonte: Autores 
Figura 10 - Normalização utilizando o método Impact 2002+ da etapa de Operação

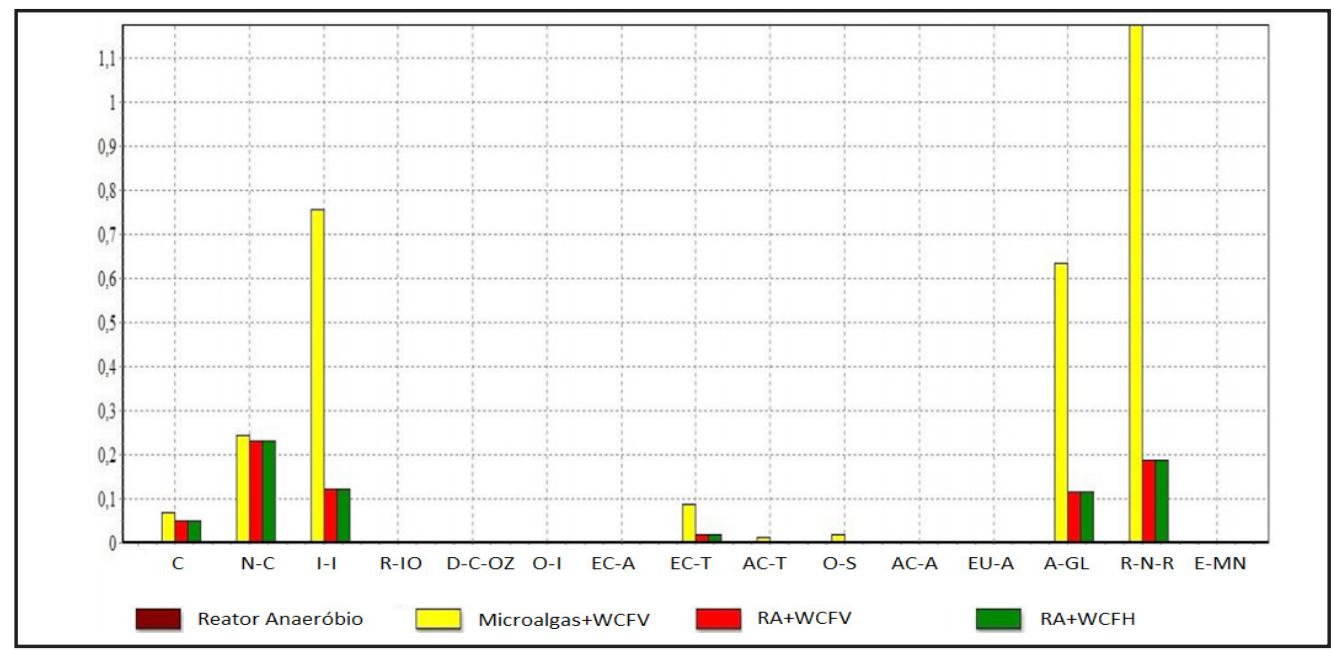

C: Carcinogênicos; N-C: Não Carcinogênicos; I-I: Inorgânicos Inaláveis; R-IO: Radiação Ionizante; D-C-OZ: Depleção da Camada de Ozônio; O-I: Orgânicos Inaláveis; EC-A: Ecotoxicidade Aquática; EC-T: Ecotoxicidade Terrestre; AC-T: Acidificação Terrestre; O-S: Ocupação do Solo; AC-A: Acidificação Aquática; EU-A: Eutrofização Aquática; A-GL: Aquecimento Global; R-N-R: Recursos Não Renováveis; E-MN: Extração Mineral Fonte: Autores

Também se observou que o sistema anaeróbio contribuiu mais significativamente na categoria de impacto Aquecimento Global, fato constatado também por Lutterbeck et. al. (2017) que analisou um sistema de wetlands precedido de tratamento anaeróbio com uma vida útil de 10 anos, sendo que neste sistema a unidade anaeróbia foi responsável pela maior parte dos impactos ambientais relacionados com as Alterações Climáticas.

Este fato já foi relatado também por outros autores, como por exemplo, Machado et.al. (2007) que através de avaliação do ciclo de vida constatou que os processos de lodos ativados apresentam os maiores impactos em comparação aos Wetlands Construídos devido ao consumo de energia necessário para a aeração.

As alternativas de tratamento de efluentes mais ecologicamente corretas foram as baseadas na natureza (wetlands construídos e lagoa de alta taxa de produção de algas), enquanto a estação convencional de tratamento de águas residuais (lodo ativado) obteve os piores resultados devido ao alto consumo de eletricidade e produtos químicos, sendo entre 2 e 5 vezes maior do que o gerado pelos sistemas baseados na natureza, dependendo da categoria de impacto (GARFÍ et. al., 2017).

Os bancos de dados utilizados pelo software SimaPro 8.01 são de uma matriz energética diferente da brasileira. Destaca-se a etapa anaeróbia pontuando significativamente na categoria Mudanças Climáticas devido à emissão de gases como o metano. Propõem-se para trabalhos futuros o aproveitamento energético deste gás, que poderia inclusive ser interligado ao sistema de recirculação das Microalgas.

Conforme Hospido, et. al. (2007) e Gallego, et. al. (2008), ambos citados por Lopes (2014), em estudos de ACV realizados em países europeus, aplicados a Esta-

Figura 11 - Ponderação utilizando Impact 2002+ para a etapa de Operação

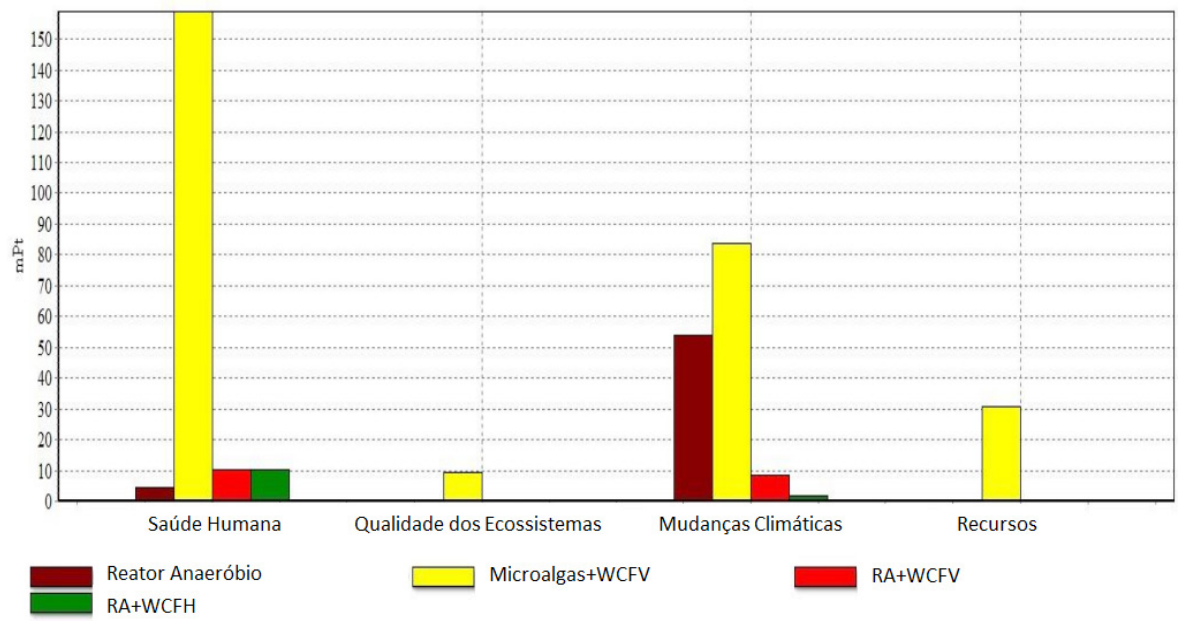


ções de Tratamento de Esgoto, apontaram a produção de energia como o processo de maior contribuição também para a categoria de acidificação, devido a dependência de matrizes energéticas oriundas de combustíveis fósseis que liberam $\mathrm{SO}_{2}$ na combustão. No presente trabalho notou-se que esse fator foi um dos mais impactantes em outras categorias também.

Conforme Campolina Et. al.(2015) É importante saber que os bancos de dados possuem caráter regional e seus dados devem ser analisados, pois o conjunto de dados de um banco de dados pode não cobrir exatamente o sistema estudado, afetando os resultados. Países em desenvolvimento têm menos interesse em assuntos relacionados à ACV, como a criação e divulgação de banco de dados de Inventário de Ciclo de Vida de processos ou produtos (CAMPOLINA et. al., 2015). O Brasil não possui um método de avaliação de impactos do ciclo de vida específico para as condições brasileiras, orienta-se utilizar mais de um método de AICV para obtenção de decisões mais confiáveis e com incertezas menores (PIEKARSKI et. al., 2012).

\section{Conclusões}

Os sistemas analisados se apresentaram minimamente impactantes, dentro de uma perspectiva geral, isso pode ser comprovado pela operação durante o período de 20 anos que consegue ter menor impacto do que a etapa de construção. Isso ocorre devido ao fato de que na operação não se utiliza nenhum tipo de produto químico e uma quantidade muito pequena de energia elétrica. Além disso, são sistemas que se integram a paisagem natural e formam pequenos ecossistemas que se utilizam de mecanismos que ocorrem em locais naturais para depuração de efluentes.

Sugere-se para a maior sustentabilidade dos sistemas de tratamento analisados o estudo da utilização de materiais provenientes dos resíduos da construção civil, devidamente classificados, segregados e cominuídos, para a utilização como material suporte nos Wetlands, reaproveitando materiais e diminuindo a dependência de extração de novos recursos. Em relação ao uso de plásticos sugerem-se estudos para a utilização de plásticos mais biodegradáveis e a redução do uso deste tipo de material.

Outro fato importante foi à ação dos gases emitidos pelo Sistema RA (metano principalmente) em relação à categoria Alterações Climáticas, para a solução deste problema indica-se a queima para tornar esse gás menos agressivo ou o aproveitamento energético do mesmo para a recirculação do Sistema MA+WCFV, o que eliminaria a dependência de fontes energéticas não renováveis.

Os mecanismos que ocorrem na natureza nos guiam na busca de soluções sustentáveis para os problemas criados pela sociedade moderna. Através da engenharia podemos aperfeiçoar esses sistemas para que se tornem altamente eficazes no processo de depuração de efluentes, mas também que não deixem de ser um ecossistema integrado a paisagem com impactos extremamente reduzidos, em consonância com objetivos de uma sociedade consciente do seu papel na construção de um planeta mais equilibrado e justo para todos.

\section{Agradecimentos}

Agradecimento ao Laboratório de Tratamento de Água e Efluentes, Laboratório de Resíduos Sólidos, ao Departamento da Engenharia ambiental e ao do Programa de Pós Graduação em Tecnologia Ambiental. Ao CNPq pelo auxílio financeiro e a CAPES pela bolsa concedida.

\section{Referências}

BRASIL. NBR ISO 14040: Gestão ambiental - Avaliação do ciclo de vida - Princípios e estrutura. Rio de Janeiro, 2009.

BRASIL. NBR ISO 14044: Gestão Ambiental - Avaliação do Ciclo de Vida - Requisitos e Orientações. Rio de Janeiro, 2009.

CAMPOLINA, J. M.; SIGRIST, C. S. L.; MORIS, V. A. S. Uma revisão de literatura sobre softwares utilizados em estudos de Avaliação do Ciclo de Vida. Universidade Federal de São Carlos - Campus Sorocaba, SP. Revista do Centro de Ciências Naturais e Exatas - UFSM Santa Maria Revista Eletrônica em Gestão, Educação e Tecnologia Ambiental da UFSM Santa Maria e-ISSN 22361170 - V. 19, n. 2, mai-ago. p 735-750 - 2015.

COROMINAS J. et. al. Life cycle assessment applied to wastewater treatment: State of the art. Disponível em journal homepage: www.elsevier.com/locate/watres. Elsevier, 2013.

COSTA, M. P. S. Avaliação do potencial de plantas nativas do Brasil no tratamento de esgoto doméstico e efluentes industriais em wetlands construídos. Campinas, SP: [s. n.], 2004.

DiNiS, M. A.; MONTEIRO, A.; BOAVENTURA, R. Tratamento de águas residuais: o papel das microalgas. Revista da faculdade de ciência e tecnologia, Porto, v. 1, p. 41-54, 2004.

FUCHS V. J.; MIHELCIC, J. R.; GIERKE J. S.; Life cycle assessment of vertical and horizontal flow constructed wetlands for wastewater treatment considering nitrogen and carbon greenhouse gas emissions. Water Reserarc, 45 pg. 2073 - 2081, 2011.

GARFÍ, M.; FLORES, L.; FERRER, I. Life Cycle Assessment of wastewater treatment systems for small communities: Activated sludge, constructed wetlands and high rate algal ponds. Journal of Cleaner Production 161, pg. 211 e 219, 2017. 
GEORGIN, J.; LAZZARI, L.; CABRAL, J. C.; MARANGONI, L. D. Brasil: $O$ acesso universal ao saneamento básico. Revista Monografias Ambientais - REMOA v.13, n.4, p.3649-3654 set-dez., 2014.

GUtierrez, Katia G. Análise e Gerenciamento de Impactos Ambientais no Tratamento de Esgoto Doméstico mediante Avaliação de Ciclo de Vida. Tese (Doutorado) - Programa de Pós-graduação em Saneamento, Meio Ambiente e Recursos Hídricos da Universidade Federal de Minas Gerais, Belo Horizonte, 2014.

IPCC - Intergovernmental Panel on Climate Change. Adoption and acceptance of the "2013 supplement to the 2006 guidelines: wetlands”. Accepted Report. Thirty-seventh session of the IPCC. Georgia, $14-18$ October 2013.

LOPES, Thaís A. S. Avaliação do ciclo de vida de uma ETE composta por Reator UASB seguido de Wetlands Construídos. 2014. Dissertação (Mestrado) - Universidade Federal da Bahia, Escola Politécnica, Salvador, 2014.

LOSPSIK, K. Life cycle assessment of small-scale constructed wetland and extended aeration activated sludge wastewater treatment system. International Journal Environmental Science and Technology. DOI 10.1007/s13762-012-0159-y, 2013.

LUTTERBECK, C. A., KIST, L. T., LOPEZ, D. R., ZERWES, F. V., \& MACHADO, Ê. L. (2017). Life cycle assessment of integrated wastewater treatment systems with constructed wetlands in rural areas. Journal of Cleaner Production, 148, 527-536. doi:10.1016/j.jclepro.2017.02.024.

MACHADO, A. P.; URBANO, L.; BRITO, A. G.; JANKNECHT, P.; SALAS, J. J.; NOGUEIRA, R. Life cycle assessment of wastewater treatment options for small and decentralized communities. Water Science \& Technology Vol. 56, No. 3, pg. 15-22, 2007.

PHILIPPI, L. S.; SEZERINO, P. H. Aplicação de sistemas tipo wetlands no tratamento de águas residuárias: utilização de filtros plantados com macrófitas. Florianópolis: Editora do Autor, 2004.

PHILIPPI, L. S.; SEZERINO, P. H. Aplicação de sistemas tipo wetlands no tratamento de águas residuárias: utilização de filtros plantados com macrófitas. Florianópolis: Universidade Federal de Santa Catarina, 2007.

PIEKARSKI, C. M.; LUZ, L. M.; ZOCCHE, L.; FRANCISCO, A. C. Métodos de Avaliação de Impactos do Ciclo de Vida: Uma Discussão para Adoção de Métodos nas Especificidades Brasileiras. Revista Gestão Industrial. Universidade Tecnológica Federal do Paraná - UTFPR, 2012.
SILVA, E. A.; NETO, J. M. M. Impactos ambientais da produção de garrafas de polietileno numa indústria de Teresina-PI. Departamento de Recursos Hídricos, Geotecnia e Saneamento Ambiental, Universidade Federal do Piauí - UFPI, Teresina, PI, Brasil, 2015.

SOARES, Rosa de Jesus B. Avaliação das Possibilidade de Tratamento de um Efluente Piscícola Marinho por Microalgas. Dissertação (Mestrado em Hidrobiologia) - Faculdade de Ciências da Universidade do Porto, Departamento de Zoologia e Antropologia Faculdade de Ciências da Universidade do Porto, Porto, 2000.

SOUSA, Catarina V. Microalgas: do tratamento de efluentes para a biorrefinaria. Dissertação (Mestrado em Energia e Bioenergia) - Universidade Nova de Lisboa, Faculdade de Ciências e Tecnologia, 2014. 